\title{
Genetic structure of Mugil cephalus L. populations from the northern coast of Egypt
}

\author{
Mahmoud Magdy ${ }^{1}$, Mariam Gergis Eshak ${ }^{2}$ and Mohamed Abdel-Salam Rashed ${ }^{2}$ \\ 1. Department of Genetics, Faculty of Agriculture, Ain Shams University, 68 Hadayek Shubra, 11241 Cairo, Egypt; \\ 2. Department of Cell Biology, National Research Centre, Dokki, Giza, Egypt. \\ Corresponding author: Mariam Gergis Eshak, e-mail: mgergis@yahoo.com, MM: m.elmosallamy@agr.asu.edu.eg, \\ MAR: rashed50@yahoo.com \\ Received: 19-06-2015, Revised: 15-11-2015, Accepted: 30-11-2015, Published online: 15-01-2016
}

doi: 10.14202/vetworld.2016.53-59 How to cite this article: Magdy M, Eshak MG, Rashed MA (2016), Genetic structure of Mugil cephalus L. populations from the northern coast of Egypt, Veterinary World 9(1): 53-59.

\begin{abstract}
Aim: The gray mullet, Mugil cephalus, has been farmed in semi-intensive ponds with tilapia and carps in Egypt for years. The current study used the fluorescent amplified fragment length polymorphism (F-AFLP) technique to search for genetic differences between the populations of $M$. cephalus in the northern region of Egypt and to detect the gene flow between sampled locations and the homogeneity within M. cephalus genetic pool in Egypt.
\end{abstract}

Materials and Methods: To fulfill the study objectives 60 (15/location) samples were collected from four northern coast governorates of Egypt (Alexandria "sea," Kafr El-Sheikh "farm," Damietta "farm" and Port Said "sea"). Three replicates of bulked DNA (5 samples/replicate) for each location were successfully amplified using the standard AFLP protocol using fluorescent primers. DNA polymorphism, genetic diversity, and population structure were assessed while positive outlier loci were successfully detected among the sampled locations. Based on the geographical distribution of sampling sites, the gene flow, the genetic differentiation, and correlations to sampling locations were estimated.

Results: A total of 1890 polymorphic bands were scored for all locations, where $765,1054,673$, and 751 polymorphic bands were scored between samples from Alexandria, Kafr El-Sheikh, Damietta and Port Said, respectively. The effective number of alleles $\left(\mathrm{n}_{\mathrm{e}}\right)$ for all bulked samples combined together was 1.42. The expected heterozygosity under HardyWeinberg assumption $\left(\mathrm{H}_{\mathrm{e}}\right)$ for all bulked samples combined together was 0.28 . Bulked samples from Damietta yielded the lowest $\mathrm{n}_{\mathrm{e}}(1.35)$ and the lowest $\mathrm{H}_{\mathrm{e}}(0.23)$ when inbreeding coefficient $\left(\mathrm{F}_{\mathrm{IS}}\right)=1$. Bulked samples from Kafr El-Sheikh scored the highest $n_{e}(1.55)$ and the highest $H_{e}(0.37)$. Bulked samples from Alexandria scored 1.40 for $n_{e}$ and 0.26 for $\mathrm{H}_{e}$, while bulked samples from Port Said scored 1.39 for $\mathrm{n}_{e}$ and 0.26 for $\mathrm{H}_{e}$. The observed bulked samples formed three sub-population groups, where none is limited to a certain sampling location. A high differentiation among locations was detected, however, is not fully isolating the locations. Gene flow was 0.58 . Positive outliers loci (117) were detected among the four sampled locations while weak significant correlation $(r=0.15, p=0.03)$ was found for the distance between them.

Conclusion: Even though this species is cultivated in Egypt, the wild population is still present and by the current study a flow of its genes is still exchanged through the northern coast of Egypt. Which contribute to the cultivated populations leading to heterogeneity in its genetic pool and consequently affects the production consistency of M. cephalus in Egypt.

Keywords: fluorescent amplified fragment length polymorphism, isolation by distance, Mantel test, marine fish, Mugil cephalus, natural selection pressure, population structure.

\section{Introduction}

The gray mullet, Mugil cephalus Linnaeus, is commonly referred to as the striped, gray, or black mullet [1]. The gray mullet has been farmed for centuries in extensive and semi-intensive ponds in many countries. Traditional aquaculture methods employed for raising mullet are now advanced, especially in Italy. Flathead gray mullet is a very important aquaculture species in Egypt, where its farming has been traditional in the "hosha" system in the delta region for centuries. Since the early 1960s, flathead gray

Copyright: Magdy et al. Open Access. This article is distributed under the terms of the Creative Commons Attribution 4.0 International License (http://creativecommons.org/licenses/by/4.0/), which permits unrestricted use, distribution, and reproduction in any medium, provided you give appropriate credit to the original author(s) and the source, provide a link to the Creative Commons license, and indicate if changes were made. The Creative Commons Public Domain Dedication waiver (http://creativecommons.org/ publicdomain/zero/1.0/) applies to the data made available in this article, unless otherwise stated. mullet has also been cultured in semi-intensive ponds with tilapia and carps in Egypt [2].

Mugil cephalus is cosmopolitan in the coastal waters of most tropical and subtropical zones and it is commonly found between $42^{\circ} \mathrm{N}$ and $42^{\circ} \mathrm{S}$ [3]. It is catadromous, frequently found coastally in estuaries and freshwater environments. Adult mullet have been found in waters ranging from zero salinity to $75 \%$ while juveniles can only tolerate such wide salinity ranges after they reach lengths of 4-7 cm. Flathead gray mullet is a diurnal feeder, consuming mainly zooplankton, dead plant matter, and detritus. Mullet have thick-walled gizzard-like segments in their stomach along with a long gastrointestinal tract that enables them to feed on detritus. Trials on the artificial propagation of flathead gray mullet have been carried out, but most of the commercial aquaculture production of flathead gray mullet still depends on fry collected from the wild, which is cheaper. 
Several population genetic studies targeted the gray Mullet habitat in the Mediterranean Sea, Atlantic Ocean and, to a lesser extent, East Pacific and Indian Oceans, as a model of study in order to obtain more information for the biodiversity conservation and fishery management. These studies included allozyme analysis, biochemical markers and mitochondrial DNA sequences [4-12], and more recently, the amplified fragment length polymorphism (AFLP) [13].

The AFLP technique is widely used in phylogenetic and population genomics studies, particularly in non-model organisms for which no prior DNA sequence information is available [14]. Wide multi-locus screening (also known as genome scan) of the locus-specific signature can reflect efficiently the adaptive divergence and genetic differentiation within a population [15]. AFLP-based genome scans have been used successfully to detect genetic differentiation due to adaptation to altitude, adaptation to soil type, insecticide resistance or ecotype divergence [16-22]. The most studies using population genomics approaches conclude that a substantial proportion of the genomes analyzed shows potential signatures of selection (about $5 \%$ of the analyzed loci; Nosil et al. [23]).

The objectives of this study were to use fluorescent AFLP based genome scanning to search for genetic differences within and between the sampled populations of $M$. cephalus and; to detect the gene flow between sampled locations and the homogeneity within M. cephalus genetic pool in the northern region of Egypt.

\section{Materials and Methods}

\section{Ethical approval}

The catching of the fish material used in the current study was permitted by the General Authority for Fish Resources Development, Ministry of Agriculture, Egypt and the Animal research ethics approval sub-committee of the Genetics department committee, Faculty of Agriculture, Ain Shams University, Egypt.

\section{Sampling and DNA extraction}

Fish samples were gathered from four locations along the northern coast governorates of Egypt (Location 1: Alexandria, sea "latitude: 31.200 and longitude: 29.919," Location 2: Kafr El-Sheikh, farm "latitude: 31.106 and longitude: 30.942," Location 3: Damietta, farm "latitude: 30.046 and longitude: 31.254 " and Location 4: Port Said, sea "latitude: 31.418 and longitude: 31.814"; Figure-1). The DNA extractions were carried out from fins of 60 collected fish samples (15/location) using Wizard $^{\circledR}$ Genomic DNA Purification Kit (PROMEGA, USA) by following the manufacturer's manual. DNA quality was then tested using agrose gel electrophoresis (1\%) contain $1 \mu 1$ of ethidium bromide $(100 \mathrm{mg} / \mathrm{ml})$, and electrophoresed for $1 \mathrm{~h}(4 \mathrm{~V} / \mathrm{cm})$. When successful, DNA was bulked in three replicates ( 5 samples/replicate), that lead to 12 bulked samples (3-bulked sample/location).

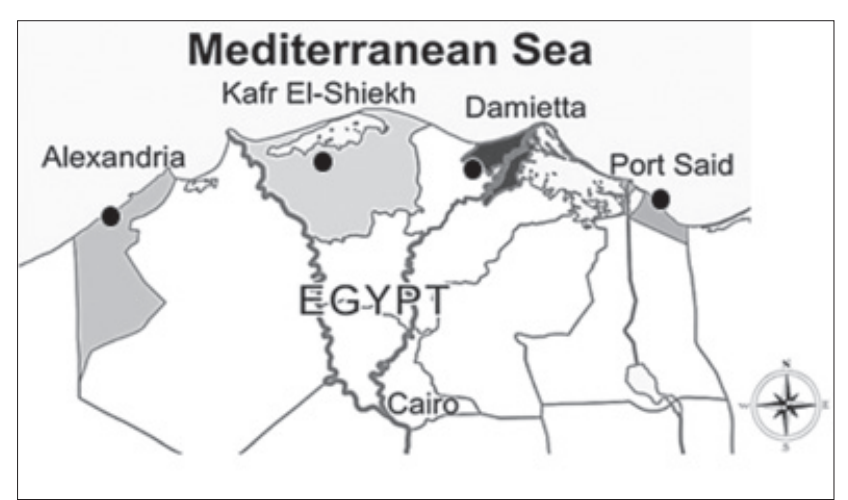

Figure-1: Sampling location along the northern coast governorates of Egypt (Alexandria "sea," Kafr El-Sheikh "farm," Damietta "farm" and Port Said "sea").

\section{AFLP-polymerase chain reaction (PCR)}

The original protocol of Vos et al. [14] was followed using fluorescent primers instead of radioactive agents. All primers and adaptors were synthesized (Invitrogen, UK) and prepared as recommended (Table-1). Six different selective PCR combinations $(3 \mathrm{Eco}+\mathrm{NNN} \times 2 \mathrm{Mse}+\mathrm{NNN}$ primers $)$ were amplified using the original PCR program. Private Service was contracted to visualize the amplified products using ABI3730 DNA analyzer (Applied Biosystems, USA) with a size standard GS500-LIZ (Macrogen Genescan Service, Korea).

\section{Data analysis \\ Band scoring}

Automated AFLP scoring was performed using two programs Peak Scanner ${ }^{\mathrm{TM}}$ (Applied Biosystems, USA) for peak calling and Rawgeno V2 for automated scoring, according to the software's manuals. The analysis of the AFLP data was based on the band-binary criterion (i.e. codifying the detected bands to, 1 when the presence and 0 when absent) and processed according to Bonin et al. [24].

\section{Genetic diversity and population structure}

To investigate the genetic structure, Bayesian clustering method was applied by using Structure V2.2 [25]. Triple independent simulations were performed per each assumed number of sub-populations $\mathrm{K}(\mathrm{K}=1$ to 6$)$. Parameters were set as the following burn-in period of 10,000 out of 100,000 MCMC iterations, and admixture ancestry model was set on.

\section{Outlier loci detection}

This procedure identifies loci which exhibit higher or a lower fixation index $\left(\mathrm{F}_{\mathrm{ST}}\right)$ values than the great majority of neutral markers. Mcheza software [26] was used to detect positive outliers considering only polymorphic loci. Under the default parameters, Mcheza was run five times with 100,000 simulations at $100 \%$ confidence limit. Loci that constantly appeared to be an outlier in each run were included in the genetic differentiation analyses. 
Genetic differentiation, gene flow and geographical influence

Analysis of molecular variance (AMOVA) was performed to test the population genetic differentiation by using Arlequin V3.5 [27]. The significance of $\mathrm{F}_{\mathrm{ST}}$ was tested with 10000 permutations for the detected AFLP loci. Gene flow (Nm) based on $\mathrm{F}_{\mathrm{ST}}$ value was estimated using AFLP-Surv [28]. The effect of the geographical distance between sampled locations on the distribution of the genotypes of M. cephalus was tested using Mantel test (to measure the association between two matrices) implemented in GenAlEx V6 [29]. The genetic distance and log (genetic distance) matrices of AFLP all loci and AFLP positive outlier loci were tested against the geographical distance and the log (geographical distance). Data and $\log$ data were used to find which were the most appropriate to represent a better correlation using Mantel test [30]. The significance of the correlation value was tested with 10,000 permutations.

\section{Results}

\section{Fragment analysis and band scoring}

PCR amplification was successful for six pairs of AFLP selective primers. Band scoring for each primer pair gathered bands between 50 and $650 \mathrm{bp}$ (Figure-2). A total of 1890 polymorphic bands were scored from all primer pairs for all the 12 bulked samples. Polymorphic bands for each location were 765, 1054, 673 and 751 for Alexandria, Kafr El-Sheikh, Damietta and Port Said, respectively. The mean band presence was $\sim 799$ while the mean fragment size was $\sim 360 \mathrm{bp}$ with a standard deviation of $\sim 160 \mathrm{bp}$. A weak significant negative correlation was found between fragment sizes and frequencies $(\mathrm{r}=-0.19 ; \mathrm{p}<0.00)$.

\section{Genetic diversity and population structure}

The effective number of alleles $\left(n_{\mathrm{e}}\right)$ for all bulked samples combined was 1.42. The expected heterozygosity under Hardy-Weinberg assumption $\left(\mathrm{H}_{\mathrm{e}}\right)$ for all bulked samples combined together was 0.28 . Bulked samples from Damietta yielded the lowest $n_{e}(1.35)$ and the lowest $\mathrm{H}_{\mathrm{e}}(0.23)$ when $\mathrm{F}_{\mathrm{IS}}=1$. Bulked samples from Kafr El-Sheikh scored the highest $\mathrm{n}_{\mathrm{e}}$ (1.55) and the highest $\mathrm{H}_{\mathrm{e}}(0.37)$. Bulked samples from Alexandria scored 1.40 for $n_{e}$ and 0.26 for $\mathrm{H}_{e}$, while bulked samples from Port Said scored 1.39 for $\mathrm{n}_{\mathrm{e}}$ and 0.26 for $\mathrm{H}_{\mathrm{e}}$ (Table-2).

The highest average of "estimated Ln probability score" with the lowest variance, sub-population number estimated by the Bayesian inference was $\mathrm{K}=3$, indicating that the observed bulked samples most probably originated from three sub-populations (groups; Figure-3).

Group 1 possesses the highest number of individuals (8) regardless of its geographical location. These are bulked samples number 1 and 2 (Alexandria), 5 and 6 (Kafr El-Sheikh), 8 (Damietta) and 10, 11 and 12 (Port Said). Group 2 consists of a unique bulked sample number 4 from Kafr El-Sheikh location. Group 3 consists of three bulked samples that are number 3 (Alexandria) and 7 and 9 (Damietta). The only homogeneous location that belongs to a certain group was Port Said sampling location (Figure-4).

\section{Detection of positive selection loci}

The AFLP data set were analyzed for outlier loci detection by using the Mcheza software between

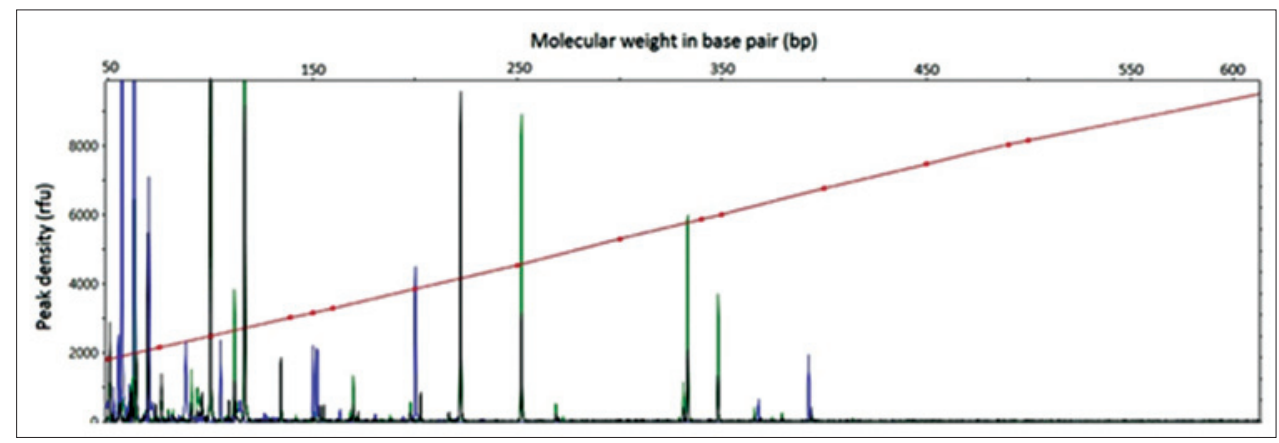

Figure-2: Fragment analysis chromatogram example of bulked sample no. 1 from Alexandria. Multiplexed selective amplified fragment length polymorphism-polymerase chain reaction of: FAM-Eco-ACA $\times$ Mse-CAA (blue peaks), HEX-EcoAGG $\times$ Mse-CAA (green peaks) and CY3-Eco-ATA $\times$ Mse-CAA (black peaks), are shown. Only peaks within 50-600 bp were considered.

Table-1: Sequence 5'- 3' of primers and adaptors used to establish the AFLP-PCR technique according to the original protocol of Vos et al. [14].

\begin{tabular}{|c|c|c|c|}
\hline Oligo & $5^{\prime}$ - sequence - $3^{\prime}$ & Oligo & $5^{\prime}$ - sequence - $3^{\prime}$ \\
\hline MseI-Adap1 & GACGATGAGTCCTGAG & EcoRI-Adap1 & CTCGTAGACTGCGTACC \\
\hline MseI-Adap2 & TACTCAGGACTCAT & EcoRI-Adap2 & AATTGGTACGCAGTC \\
\hline Mse-C & GATGAGTCCTGAGTAAC & Eco-A & GACTGCGTACCAATTCA \\
\hline Mse-CAA & GATGAGTCCTGAGTAACAA & ECO-ACA & FAM-GACTGCGTACCAATTCACA \\
\hline \multirow[t]{2}{*}{ Mse-CTC } & GATGAGTCCTGAGTAACTC & Eco-AGG & HEX-GACTGCGTACCAATTCAGG \\
\hline & & Eco-ATA & CY3-GACTGCGTACCAATTCATA \\
\hline
\end{tabular}

Selective nucleotide are in bold. AFLP=Amplified fragment length polymorphism, $\mathrm{PCR}=$ Polymerase chain reaction 


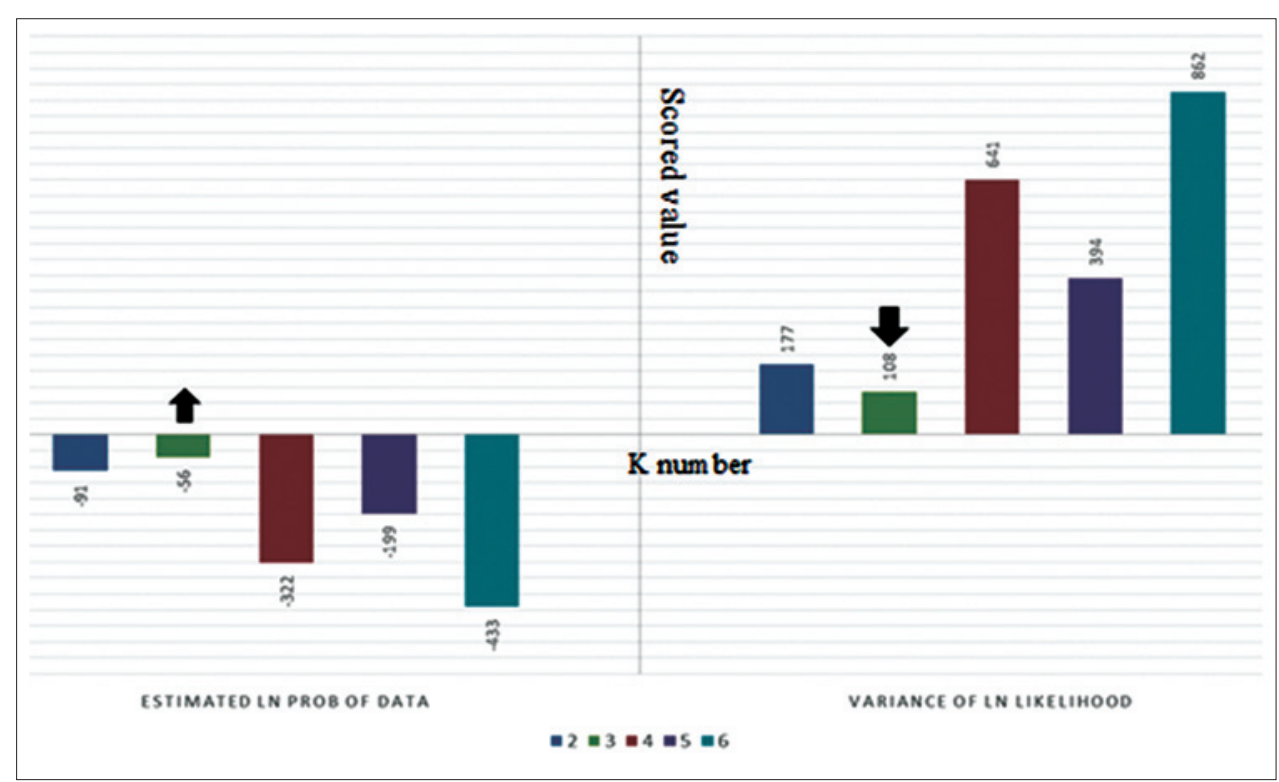

Figure-3: Graphical plotting of structure software output scores based on amplified fragment length polymorphism loci. Estimated In probability (LnP) and variance of In likelihood (VLn) for $\mathrm{K}=[2-6]$, are shown. $\mathrm{K}=3$ shows the lowest VLn and highest LnP.

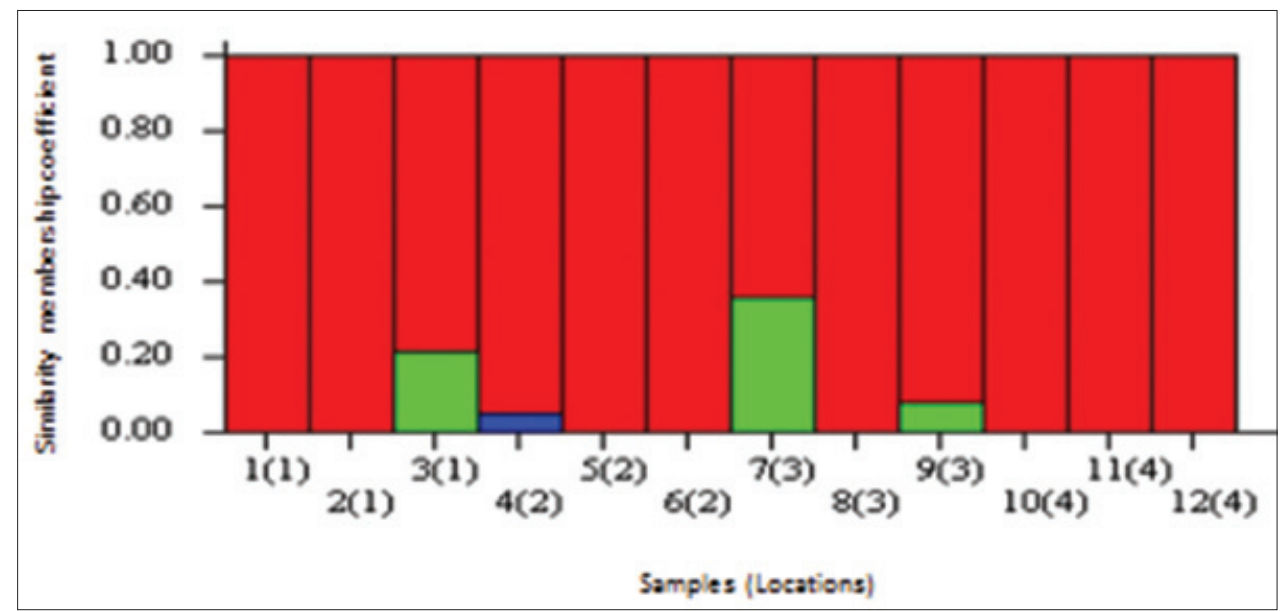

Figure-4: Amplified fragment length polymorphism marker-based structure bar plot graph of $K=3$, for 12 samples in 4 locations. Samples are ordered by group assignment and locations are indicated between brackets.

Table-2: Genetic diversity and DNA polymorphism based on AFLP bands.

\begin{tabular}{lccccc}
\hline Parameter/location & Alexandria & Kafr El-Sheikh & Damietta & Port said & All samples \\
\hline Number of polymorphic bands & 765 & 1054 & 673 & 751 & 1890 \\
Mean heterozygosity $\left(\mathrm{H}_{\mathrm{e}}\right)$ & 0.26 & 0.37 & 0.23 & 0.26 & 0.28 \\
Standard deviation $\left(\mathrm{H}_{\mathrm{e}}\right)$ & 0.32 & 0.33 & 0.31 & 0.32 & 0.32 \\
Mean effective number of alleles $\left(\mathrm{n}_{\mathrm{e}}\right)$ & 1.40 & 1.55 & 1.35 & 1.39 & 1.42 \\
Standard deviation $\left(\mathrm{n}_{\mathrm{e}}\right)$ & 0.49 & 0.49 & 0.47 & 0.48 & 0.48 \\
\hline
\end{tabular}

AFLP $=$ Amplified fragment length polymorphism

the four locations. Across the 16 pairwise analyses between the four groups, 117 out of 1890 polymorphic loci $(6.19 \%)$ were identified as outlier loci under directional selection at the $99.5 \%$ confidence level (Figure-5). The 117 loci appeared constantly as outlier loci among the four geographical locations in each run.

\section{Genetic differentiation, gene flow and geographical influence}

An AMOVA test was used to measure the changes in the pairwise differentiation of the $F_{\mathrm{ST}}$ for the AFLP dataset. $\mathrm{F}_{\mathrm{ST}}$ of $0.46(\mathrm{p}<0.00)$, partitioned into a major genetic variation originated within locations, accounting for $53 \%$ of the total variations, while $47 \%$ of the genetic variation occurred among locations (Table-3). Gene flow $\left(\mathrm{N}_{\mathrm{m}}\right)$ was estimated of 0.58 based on Wright's fixation index $\left(\mathrm{F}_{\mathrm{ST}}=0.46\right)$, where " $\mathrm{N}_{\mathrm{m}}=\left[\left(1 / \mathrm{F}_{\mathrm{ST}}\right)-1\right] / 2 . "$

Partial Mantel test between the geographical distance and AFLP all loci data set for both data and $\log$ data showed no significant correlation, along 


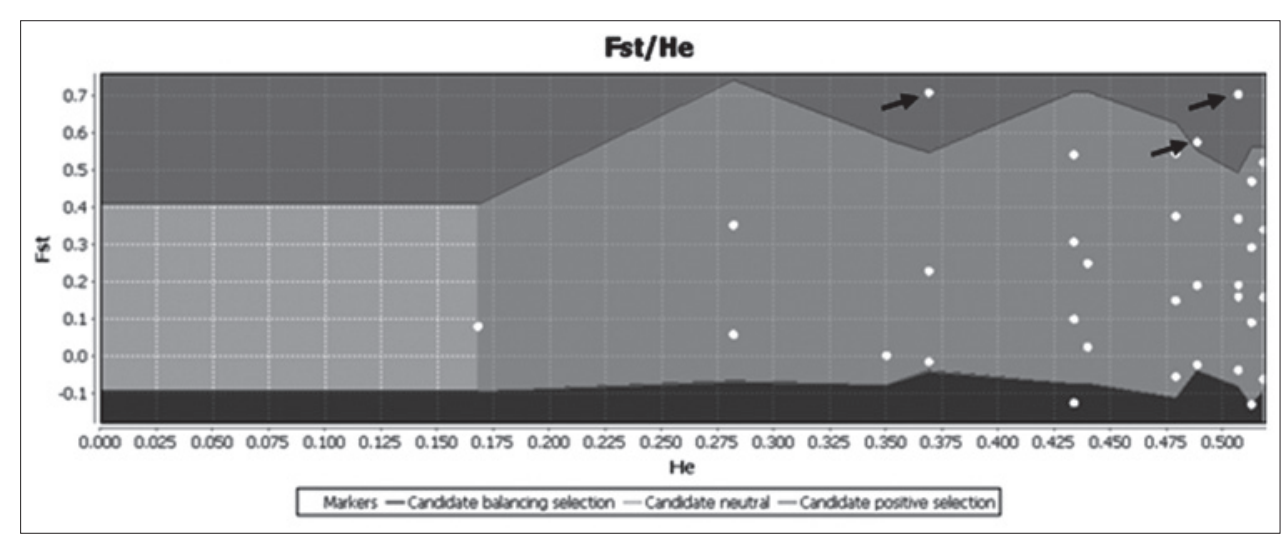

Figure-5: Graphical plot produced by Mcheza software of $F_{S T}$ values against heterozygosity $\left(H_{e}\right)$ for each of the 1890 amplified fragment length polymorphism (AFLP) loci. The lower and higher zones represent the $0.5 \%$ and $99.5 \%$ confidence intervals, respectively. Loci in the semi-dark gray zone above the $99.5 \%$ are regarded as positive outlier loci. Each dot indicates an AFLP locus, loci scored the same value appears as one dot.

Table-3: Genetic differentiation through AMOVA of M. cephalus based on the AFLP loci dataset.

\begin{tabular}{lcccc}
\hline $\begin{array}{l}\text { Source of } \\
\text { variance }\end{array}$ & df & SS & $\begin{array}{c}\text { Variance } \\
\text { components }\end{array}$ & $\begin{array}{c}\text { Percentage } \\
\text { of variation }\end{array}$ \\
\hline Among locations & 3 & 2395.58 & 193.09 & 47 \\
Within locations & 8 & 1754 & 219.25 & 53 \\
Total & 11 & 4149.58 & 412.34 & \\
\hline
\end{tabular}

$F_{S T}=0.46(p<0.00)$. The source of variance (among and within locations), the degree of freedom (df), the SS, the variance components and the percentage of variation, are shown. SS=Sum of squares, AMOVA=Analysis of molecular variance, M. cephalus=Mugil cephalus, $A F L P=A m p l i f i e d$ fragment length polymorphism

with the AFLP outlier data against the geographical data. However, weak significant correlation $(r=0.15$, $\mathrm{p}=0.03$ ) was found between $\log$ (AFLP outlier) matrix against geographical distance matrix.

\section{Discussion}

In Egypt, mullet fish especially $M$. cephalus is economically a very important fish because it has high market value and has been cultivated successfully by fish farmers [31]. Several studies targeted the species M. cephalus with many aims, however, less were concerned by its population structure and genetic diversity as it is mainly farmed. Even though, wild populations are still present and by the current study, a flow of its genes are still exchanged through the northern coast of Egypt, thus contribute to the cultivated populations.

The AFLP technique permits a genome-wide scan of the genetic variability with a high number of variable markers. Therefore, there is a relative good chance to detect markers under selection either directly or because they are located near a gene under selection. The high reading output and the extensive statistical refining were expected to reflect more clearly the genetic variability of the studied samples. The mean expected heterozygosity under HardyWeinberg assumption $\left(\mathrm{H}_{\mathrm{e}}\right)$ was 0.28 , which reflects the low diversity level of $M$. cephalus genetic pool from the sampled locations. The structure program implements a model-based clustering method for inferring population structure using molecular data consisting of unlinked markers. The method was introduced by Pritchard et al. [32] and extended in sequels by Falush et al. $[33,34]$. The method application is to detect the population structure, identifying distinct genetic groups, assigning samples to sub-populations, and identifying migrants in admixed samples. The bulked samples of Groups 2 and 3 showed mixed portions of Group 1 (inferred by color), which deduce a weak attachment to its assigned cluster, and that they might be grouped to such cluster only when the information about the sampling locations was included. Samples that are genetically related are from different geographical locations, had exactly the same similarity membership coefficient (i.e., a value in which a sample is assigned to a certain group) although they originate from distant locations. Thus, multiple introductions are inferred among sampled locations of $M$. cephalus in the northern coast of Egypt. Such conclusion was further tested and proved by AMOVA.

Currently, there is increasing interest in identifying genes or outlier loci that underlie adaptations to different factors in several species $[18,35,36]$. Outlier loci are revealed by unusually high levels of population differentiation at specific marker loci $[15,37,38]$. Those loci that are involved in adaptation to local environmental conditions are indeed expected to exhibit increased differentiation among locations along with a decreased diversity within locations [18].

For example, the study of the genetic frame of adaptation to a gradient of altitude in the common frog (Rana temporaria L.) by Bonin et al. [18] showed that approximately $2 \%$ of the AFLP loci they screened exhibited elevated altitudinal differentiation. Another recent example was presented by Magdy et al. [39] on the cord moss (Funaria hygrometrica Hedw.) in which the genome scanning successfully detected loci under selection that were strongly correlated with the gradient of environmental factors in Sierra Nevada mountains. Because local adaptation and directional selection should have locus-specific effects of reducing genetic variability within populations and 
increasing differentiation between populations, loci that are outliers for these characteristics are strong candidate regions for involvement in adaptation to the certain environment.

This study is the first report on the detection of candidate loci under selection by a genome scan in the M. cephalus in the northern coast of Egypt. The AFLP genome scan analysis revealed 117 loci as under selection among a total of 1890 loci scored in this study. Meyer et al. [20] noted that the power of the analysis is directly associated with the genome coverage. These 117 loci possess a high credibility because, they were picked up by an exhaustive method (Dfdist embedded in Mcheza software), a very stringent significance criterion of $99.5 \%$ was applied, and simulations were set up to the maximum number allowed by the program. Since a high number of reasonable size bands between 150 and $600 \mathrm{bp}$ were found, the loci under selection detected here should prove to have a good reliability.

The AMOVA produces estimates of variance components and F-statistics analogs [40]. In our case, AMOVA results were significant; reflect an approximate level of differentiation among sampled locations and within each location ( $47 \%$ and 53\%, respectively). Gene flow $\left(\mathrm{N}_{\mathrm{m}}\right)$ is a major factor influencing the genetic structure and differentiation among populations. Gene flow was 0.58 , the detection of gene flow shows that the genetic differentiation among locations is not absolute. In other words, a complete reproductive isolation between the sampled locations is not the case. Wright [41] proposed that when the gene flow among the locations $\mathrm{N}_{\mathrm{m}}>1$, the homogenization is the result. When $\mathrm{N}_{\mathrm{m}}<1$, the locations can be strongly differentiated. According to these criteria, strong genetic differentiation exists among the studied locations.

To elucidate the genetic bases of adaptation to different environments represents a goal of central importance and interest in evolutionary biology [15]. Testing the correlation between the differences in geographic distance among sampled location and the genetic diversity of each sampled location would greatly indicate the geographic influence on the gene flow and further the population structure. Such test is usually known as isolation by distance and was extensively reported during the last decade [42]. The presence of a correlation between the genetic variation and the geographic distance (even though it is weak) along with the detected gene flow between the studied locations, it supports the presence of a certain gene flow limited by the distance between the sampling locations due to some environmental obstacles more than biological reasons. The outliers contribute to such assumption, as it raise the presence of selection mechanism based on the location conditions. However, it is not absolute that wild populations might decrease the isolation level through the gene flow caused by its movement along the northern coast attracted by the zooplankton, dead plant matter, and detritus near the shore, and being used as fries for cultivation [2].
As the detected AFLP loci are likely located in non-coding DNA, some of the outlier loci may only exhibit the signature of selection because they are linked to the actual target [43]. Although it is difficult to know the location and function of the detected outlier loci, the genome scan of $M$. cephalus still offers a window to unravel the genetic basis of fish adaptation without known phenotypes and whole genome sequences. Nowadays, the AFLP primers that were used to amplify the identified outlier loci can be used to construct a reduced representation library of the M. cephalus genome using next-generation sequencing technology [44].

\section{Authors' Contributions}

MM has carried out the experimental work in the MAR laboratory and then he prepared the manuscript, while ME has checked the manuscript and polished English language. All authors read and approved the final manuscript.

\section{Acknowledgments}

The authors kindly acknowledge Prof. Dr. Farid Estino for his critical reviewing of the article. The current research was co-funded by the internal fund provided by the Genetics department, Faculty of Agriculture, Ain Shams University, Egypt.

\section{Competing Interests}

The authors declare that they have no competing interests.

\section{References}

1. Nelson, J.S., Crossman, E.J., Espinosa-Pérez, H., Findley, L.T., Gilbert, C.R., Lea, R.N. and Williams, J.D. (2004) Common and scientific names of fishes from the United States, Canada and Mexico. American Fisheries Society, Bethesda, Maryland.

2. FAO. (2015) Aquaculture feed and fertilizers resources information system, special profiles: Flathead grey mullet - Mugil cephalus. Available from: http://www.fao.org/fishery/culturedspecies/Mugil_cephalus/en. Accessed on 11-01-2015.

3. Thomson, J.M. (1963) Synopsis of Biological Data on the Grey Mullet: Mugil Cephalus Linnaeus 1758. Division of Fisheries and Oceanography. CSIRO, Australia. p78.

4. Crosetti, D., Avise, J.C., Placidi, F., Rossi, A.R. and Sola, L. (1993) Geographic variability in the grey mullet Mugil cephalus: Preliminary results of mtDNA and chromosome analyses. Aquaculture, 111(1): 95-101.

5. Crosetti, D., Nelson, W.S. and Avise, J.C. (1994) Pronounced genetic structure of mitochondrial DNA among populations of the circumglobally distributed grey mullet (Mugil cephalus). J. Fish Biol., 44(1): 47-58.

6. Corti, M. and Crosetti, D. (1996) Geographic variation in the grey mullet: A geometric morphometric analysis using partial warp scores. J. Fish Biol., 48(2): 255-269.

7. Rossi, A.R., Capula, M., Crosetti, D., Sola, L. and Campton, D.E. (1998a) Allozyme variation in global populations of striped mullet, Mugil cephalus (Pisces: Mugilidae). Mar Biol, 131(2): 203-212.

8. Rossi, A.R., Capula, M., Crosetti, D., Campton, D.E., and Sola, L. (1998b) Genetic divergence and phylogenetic inferences in five species of Mugilidae (Pisces: Perciformes). Mar Biol, 131(2): 213-218.

9. Rocha-Olivares, A., Garber, N.M. and Stuck, K.C. (2000) 
High genetic diversity, large inter-oceanic divergence and historical demography of the striped mullet. J. Fish Biol., 57(5): 1134-1149.

10. Huang, C., Weng, C. and Lee, S. (2001) Distinguishing two types of gray mullet, Mugil cephalus L. (Mugiliformes: Mugilidae), by using glucose-6-phosphate isomerase (GPI) allozymes with special reference to enzyme activities. J. Comp. Physiol. B., 171(5): 387-394.

11. Shen, K.N., Jamandre, B.W., Hsu, C.C., Tzeng, W.N. and Durand, J.D. (2011) Plio-Pleistocene sea level and temperature fluctuations in the northwestern Pacific promoted speciation in the globally- distributed flathead mullet Mugil cephalus. BMC Evol. Biol., 11(1): 83.

12. Durand, J.D., Blel, H., Shen, K.N., Koutrakis, E.T., and Guinand, B. (2013) Population genetic structure of Mugil cephalus in the mediterranean and Black Seas: A single mitochondrial clade and many nuclear barriers. Mar. Ecol. Prog. Ser., 474: 243-61.

13. Liu, J.Y., Lun, Z.R., Zhang, J.B. and Yang, T.B. (2009) Population genetic structure of striped mullet, Mugil cephalus, along the coast of China, inferred by AFLP fingerprinting. Biochem. Syst. Ecol., 37(4): 266-274.

14. Vos, P., Hogers, R., Bleeker, M., Reijans, M., Van de Lee, T., Hornes, M., Friters, A., Pot, J., Paleman, J., Kuiper, M. and Zabeau, M. (1995) AFLP: A new technique for DNA fingerprinting. Nuc. Acids Res., 23(21): 4407-4414.

15. Storz, J.F. (2005) Using genome scans of DNA polymorphism to infer adaptive population divergence. Mol. Ecol., 14(3): 671-688.

16. Wilding, C.S., Butlin, R.K. and Grahame, J. (2001) Differential gene exchange between parapatric morphs of Littorina saxatilis detected using AFLP markers. J. Evol. Biol., 14(4): 611-619.

17. Campbell, D. and Bernatchez, L. (2004) Generic scan using AFLP markers as a means to assess the role of directional selection in the divergence of sympatric whitefish ecotypes. Mol. Biol. Evol., 21(5): 945-956.

18. Bonin, A., Taberlet, P., Miaud, C. and Pompanon, F. (2006) Explorative genome scan to detect candidate loci for adaptation along a gradient of altitude in the common frog (Rana temporaria). Mol. Biol. Evol., 23(4): 773-783.

19. Savolainen, V., Anstett, M.C., Lexer, C., Hutton, I., Clarkson, J.J., Norup, M.V., Powell, M.P., Springate, D., Salamin, N. Baker, W.J. (2006) Sympatric speciation in palms on an oceanic island. Nature, 441(7090): 210-213.

20. Meyer, C.L., Vitalis, R., Saumitou-Laprade, P. and Castric, V. (2009) Genomic pattern of adaptive divergence in Arabidopsis halleri, a model species for tolerance to heavy metal. Mol. Ecol., 18(9): 2050-2062.

21. Paris, M., Boyer, S., Bonin, A., Collado, A., David, J.P. and Despres, L. (2010) Genome scan in the mosquito Aedes rusticus: Population structure and detection of positive selection after insecticide treatment. Mol. Ecol., 19(2): 325-337.

22. Poncet, B.N., Herrmann, D., Gugerli, F., Taberlet, P., Holderegger, R., Gielly, L., Rioux, D., Thuiller, W., Aubert, S. and Manel, S. (2010) Tracking genes of ecological relevance using a genome scan in two independent regional population samples of Arabis alpina. Mol. Ecol., 19(14): 2896-2907.

23. Nosil, P., Funk, D.J. and Ortiz-Barrientos, D. (2009) Divergent selection and heterogeneous genomic divergence. Mol. Ecol., 18(3): 375-402.

24. Bonin, A., Ehrich, D. and Manel, S. (2007) Statistical analysis of amplified fragment length polymorphism data: A toolbox for molecular ecologists and evolutionists. Mol. Ecol., 16(18): 3737-3758.

25. Hubisz, M.J., Falush, D., Stephens, M. and Pritchard, J.K. (2009) Inferring weak population structure with the assistance of sample group information. Mol. Ecol. Resour., 9(5): 1322-1332.

26. Antao, T. and Beaumont, M.A. (2011) Mcheza: A workbench to detect selection using dominant markers. Bioinformatics, 27(12): 1717-1718.

27. Excoffier, L. and Lischer, H.E. (2010) Arlequin suite ver 3.5: A new series of programs to perform population genetics analyses under Linux and Windows. Mol. Ecol. Resour., 10(3): 564-567.

28. Vekemans, X., Beauwens, T., Lemaire, M. and Roldán-Ruiz, I. (2002) Data from amplified fragment length polymorphism (AFLP) markers show indication of size homoplasy and of a relationship between degree of homoplasy and fragment size. Mol. Ecol., 11(1): 139-151.

29. Peakall, R. and Smouse, P.E. (2012) Gen Al Ex 6.5: Genetic analysis in excel. Population genetic software for teaching and research-an update. Bioinformatics, 28(19): 2537-2539.

30. Bohonak, A.J. (2002) IBD (Isolation by Distance): A program for analyses of isolation by distance. J. Hered., 93(2): 153-154.

31. Bahnasawy, M., Khidr, A.A. and Dheina, N. (2009) Seasonal variations of heavy metals concentrations in mullet, Mugil cephalus and Liza ramada (Mugilidae) from Lake Manzala, Egypt J. Aquat. Biol. \& Fish, 13(2): 81-100.

32. Pritchard, J.K., Stephens, M. and Donnelly, P. (2000) Inference of population structure using multilocus genotype data. Genetics, 155(2): 945-959.

33. Falush, D., Stephens, M. and Pritchard, J.K. (2003) Inference of population structure using multilocus genotype data: Linked loci and correlated allele frequencies. Genetics, 164(4): 1567-1587.

34. Falush, D., Stephens, M. and Pritchard, J.K. (2007) Inference of population structure using multilocus genotype data: Dominant markers and null alleles. Mol. Ecol. Notes, 7(4): 574-578.

35. Nosil, P., Egan, S.P. and Funk, D.J. (2008) Heterogeneous genomic differentiation between walking-stick ecotypes: "Isolation by adaptation" and multiple roles for divergent selection. Evolution, 62(2): 316-336.

36. Manel, S., Joost, S., Epperson, B.K., Holderegger, R., Storfer, A., Rosenberg, M.S., Scribner, K.T., Bonin, A. and Fortin, M.J. (2010) Perspectives on the use of landscape genetics to detect genetic adaptive variation in the field. Mol. Ecol., 19(17): 3760-3772.

37. Black IV, W.C., Baer, C.F., Antolin, M.F. and DuTeau, N.M. (2001) Population genomics: Genome-wide sampling of insect populations. Annu. Rev. Entomol., 46(1): 441-469.

38. Luikart, G., England, P.R., Tallmon, D., Jordan, S. and Taberlet, P. (2003) The power and promise of population genomics: From genotyping to genome typing. Nat. Rev. Genet., 4(12): 981-994.

39. Magdy, M., Werner, O., McDaniel, S.F., Goffinet, B. and Ros, R.M. (2015) Genomic scanning using AFLP to detect loci under selection in the moss Funaria hygrometrica along a climate gradient in the Sierra Nevada Mountains, Spain. Plant Biol., doi: 10.1111/plb.12381.

40. Excoffier, L., Smouse, P.E. and Quattro, J.M. (1992) Analysis of molecular variance inferred from metric distances among DNA haplotypes: Application to human mitochondrial DNA restriction data. Genetics, 131(2): 479-491.

41. Wright, S. (1931) Evolution in Mendelian populations. Genetics, 16(2): 97.

42. Jensen, J.L., Bohonak, A.J. and Kelley, S.T. (2005) Isolation by distance, web service. BMC Genet., 6(1): 13.

43. Schlötterer, C. (2003) Hitchhiking mapping-functional genomics from the population genetics perspective. Trends Genet., 19(1): 32-38.

44. Hohenlohe, P.A., Catchen, J., Cresko, W.A. (2012) Population genomic analysis of model and non model organisms using sequenced RAD tags. In: Pompanon, F., Bonin, A., editors. Data Production and Analysis in Population Genomics. Humana Press, New York, U.S.A. p235-260. 